УДК 338.2

08.00.00 Экономические науки

\section{РАЗРАБОТКА СИСТЕМЫ ПОДДЕРЖКИ ПРИНЯТИЯ РЕШЕНИЙ ДЛЯ ОЦЕНКИ УСТОЙЧИВОСТИ ПРЕДПРИЯТИЯ}

\author{
Барановская Татьяна Петровна \\ профессор
}

Иванова Елена Александровна
старший преподаватель

\author{
Канатов Артем Алексеевич \\ студент \\ Кубанский государственный аграрный универси- \\ тет, Краснодар, Россия
}

Устойчивость предприятий играет важную роль в экономической и социальной жизни всех промышленно развитых стран. Несмотря на многочисленные публикации, посвященные вопросам анализа устойчивости организаций, все еще существует неоднозначность подходов к методам анализа у разных авторов. Также для предприятий различных отраслей, форм собственности, территориально расположенных в разных регионах границы, методики и показатели оценки устойчивости могут в значительной степени варьироваться. В связи с этим возникает необходимость в разработке системы поддержки принятия решений, которая позволяла бы наиболее эффективно оценивать устойчивость как можно большего диапазона предприятий с возможностью корректировки и гибкой настройки как можно большего набора параметров. В статье описана архитектура и алгоритм работы СППР, реализующей в своем функционале следующие модель формирования исходных данных; модель формирования древовидной структуры групп показателей, на базе которых происходит оценка устойчивости; модель задания функций принадлежности нечетких множеств, задающих рекомендуемые значения показателей; модель расчета значений групп показателей и их нечетких оценок; модель графической интерпретации оценки устойчивости организации. Разработанная система прошла апробацию на базе организации ООО «Антей»

Ключевые слова: УСТОЙЧИВОСТЬ ПРЕДПРИЯТИЯ, ПОКАЗАТЕЛЬ, НЕЧЕТКОЕ МНОЖЕСТВО, ФУНКЦИЯ ПРИНАДЛЕЖНОСТИ, МОДЕЛЬ SAAS, SQLITE, C\#, TЕХНОЛОГИЯ ASP.NET»
UDC 338.2

Economic sciences

\section{DEVELOPMENT OF A DECISION SUPPORT SYSTEM FOR SUSTAINABILITY ASSESSING OF A COMPANY}

Baranovskaya Tatiana Petrovna

Doctor of Economics, professor

Ivanova Elena Alexandrovna

senior lecturer

Kanatov Artyom Alexeevich, student

Kuban State Agrarian University, Krasnodar, Russia

Sustainability of enterprises plays an important role in the economic and social life of all industrially developed countries. Despite numerous publications devoted to the analysis of the sustainability of organizations, there are still ambiguous approaches to the methods of analysis for different authors. In addition, for companies of different industries, forms of ownership, geographically located in different regions of the border, the methods and indicators for assessing sustainability can vary considerably. In this connection, there is a need to develop a decision support system that would allow the most efficient assessment of the sustainability of the largest possible range of enterprises, with the possibility of adjusting and flexibly tuning as many parameters as possible. The article describes the architecture and algorithm of the DSS, which implements the following model of initial data generation in its functional; Model of formation of a tree-like structure of groups of indicators on the basis of which the stability is assessed; Model for specifying the fuzzy sets belonging to the recommended values of the indicators; Model for calculating the values of groups of indicators and their fuzzy estimates; The model of graphical interpretation of the organization's sustainability assessment. The developed system was tested on the basis of the company called Antey LLC

Keywords: ENTERPRISE SUSTAINABILITY, INDEX, FUZZY SET, MEMBERSHIP FUNCTION, SAAS MODEL, SQLITE, “ASP.NET” TECHNOLOGY

\title{
Doi: 10.21515/1990-4665-129-078
}

\section{Понятие «устойчивость» организации в экономической литературе}


трактуется по-разному. Большинство экономистов (например, Быков Д.Ю., Коршунова Э.Т.) представляют его в узком смысле слова, смешивая с понятием финансовой устойчивости или даже со значением платежеспособности $[1,3,4]$.

Некоторые авторы, такие, как Макова М.М., Набиев А.М., Наламова О.В., Хомяченкова Н.А., наоборот, рассматривают устойчивость в более широком смысле, принимая ее не только как критерий платежной устойчивости, но и ликвидности, устойчивости имущественного положения, инвестиционной привлекательности, инновационных и рисковых характеристик $[6,7]$.

Однако во всех методиках оценка и измерение устойчивости развития проводится с использованием показателей, которые характеризуют динамику развития основных подсистем. Также широко используются так называемые агрегированные показатели - индексы.

Общую последовательность этапов оценки устойчивости по классическим методикам можно представить следующим образом (рисунок 1).

Современный российский рынок программного обеспечения на данный момент предлагает достаточно большое разнообразие продуктов, автоматизирующих анализ деятельности предприятий, но данные разработки касаются прежде всего финансового анализа организаций. При этом модули по оценке устойчивости (опять-таки, только финансовой) являются составными элементами таких приложений. Наиболее популярными на данный момент разработками являются [12]:

- программный продукт "Альт-Финансы", разработанный исследовательско-консультационной фирмой "АЛЬТ";

- программный продукт "Audit Expert", разработанный фирмой "Про-Инвест Консалтинг";

- программный комплекс "Финансовый аналитик", разработанный фирмой "ИНЭК". 


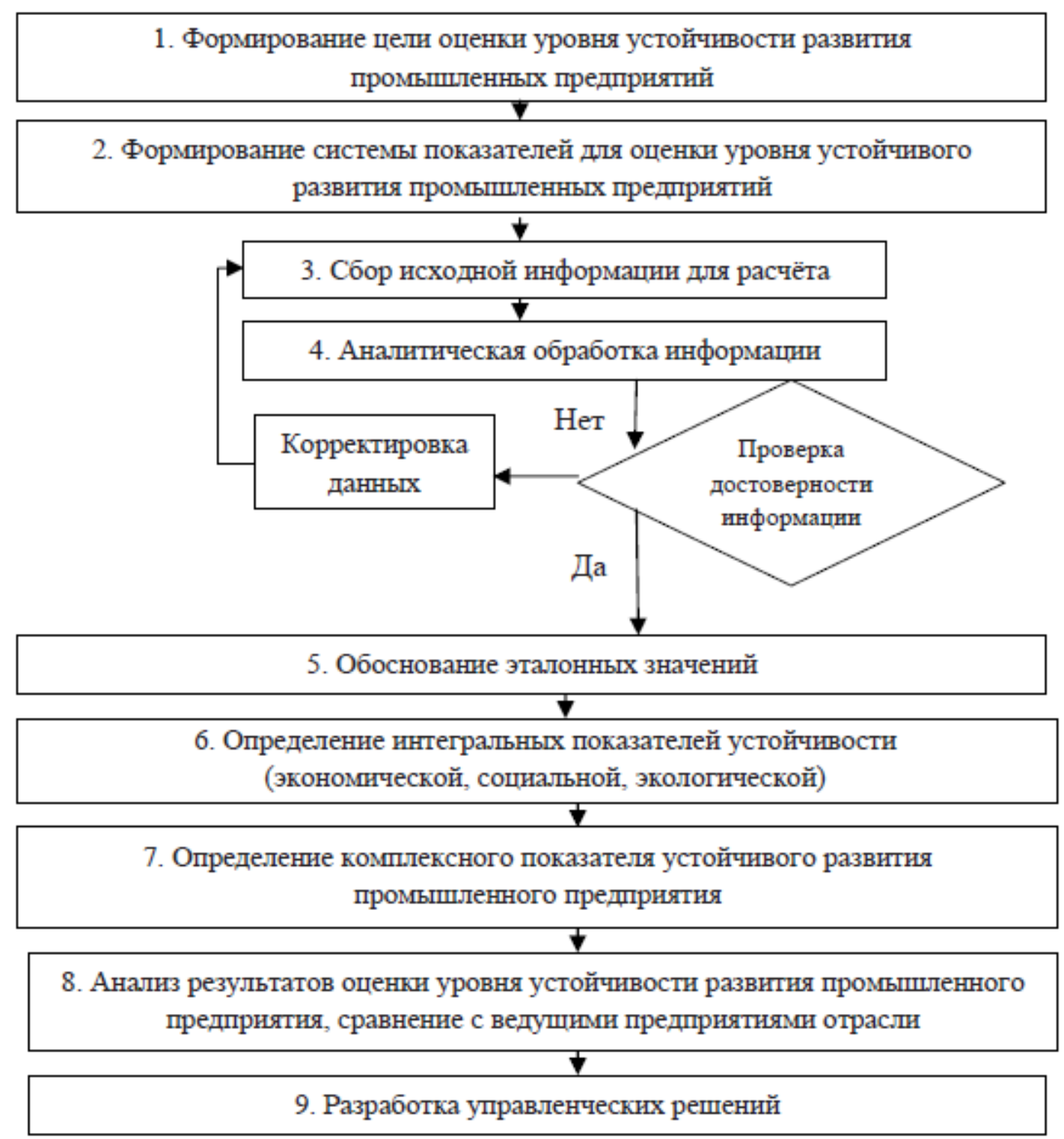

Рисунок 1- Этапы классических методик оценки уровня устойчивости развития предприятия

Bсе рассмотренные разработки имеют некоторые схожие черты. Они предназначены для проведения анализа финансового состояния предприятий (организаций). В качестве исходной информации для анализа используются данные стандартных форм бухгалтерской отчетности - Баланса, Отчета о финансовых результатах. 
Анализ состояния предприятия (организации) проводится по следующим направлениям [3]:

- структура баланса;

- ликвидность;

- финансовая устойчивость;

- прибыльность;

- оборачиваемость;

- рентабельность;

- анализ эффективности труда.

Исходя из проведенного анализа предметной области и аналогов программного обеспечения разрабатываемой СППР, можно сделать следующие выводы:

- предлагаемые различными учеными методики оценки устойчивости предприятий достаточно сильно разнятся, что приводит к сложностям и проблемам, особенно в случаях необходимости проведения сравнительной оценки устойчивости различных предприятий (тем более, если эти предприятия принадлежат к разным отраслям, организационно-правовым формам и/или территориально находятся в разных регионах);

- практически все методики оценки устойчивости предприятия основываются на вычислении и последующей оценке различных показателей, которые затем группируются (агрегируются) тем или иным способом, и полученный в результате данного процесса интегральный показатель как раз и представляет собой меру устойчивости предприятия. Набор показателей и их групп, а также способ их агрегации (свертки) в различных методиках разный;

- в нынешних условиях нестабильности и непредсказуемости экономической ситуации в стране и мире сложно задать фиксированные пороговые значения показателей предприятий различных типов, отраслей и ре- 
гионов, так как эти значения зачастую являются размытыми (нечеткими). Однако ни один из рассмотренных программных комплексов и практически ни одна из существующих методик оценки устойчивости не предполагает использования методов нечеткой математики и элементов теории нечетких множеств (за исключением попыток задать исходные показатели для оценки в виде нечетких чисел), что являлось бы в данном случае актуальным;

- практически все рассмотренные программные комплексы, позволяющие проводить оценку устойчивости предприятий, являются по своему назначению более масштабными и, соответственно, дорогими. А анализ устойчивости включен в них как отдельный модуль. При этом приложения, как правило, ограничиваются лишь оценкой финансовой устойчивости организаций;

- мало какие программные комплексы позволяют задать пользователю свои алгоритмы и формулы для расчета исходных показателей оценки устойчивости, и практически никакие не позволяют пользователю самостоятельно задать группы показателей и указать способ их дальнейшей агрегации для получения интегрального показателя оценки устойчивости;

- ни один из рассмотренных программных комплексов не предусматривает возможности работы и хранения данных в облаке. Максимум из предоставляемого функционала - это сетевые версии систем, в большинстве случаев приобретаемые за отдельную (и очень недешевую) плату.

Таким образом, можно сделать вывод о несомненной актуальности разработки системы поддержки принятия решений для оценки устойчивости предприятий.

Определим основные функциональные требования к разрабатываемой СППР:

- в базе данных должен храниться набор показателей и их групп, из которых пользователь может выбрать необходимые ему в данном конкретhttp://ej.kubagro.ru/2017/05/pdf/78.pdf 
ном случае группы, а затем добавить в каждую группу нужные ему показатели. Таким образом, пользователь сам проектирует иерархическую структуру показателей, фактически представляющую собой алгоритм оценки устойчивости предприятия. Способ агрегации показателей группы, а также всех групп между собой для получения и оценки итогового показателя также должен задаваться пользователем. Список показателей и групп в базе данных будет пополняться и редактироваться;

- исходными данными для оценки устойчивости может выступать практически любая информация из различных видов отчетности. Эту информацию необходимо загружать из базы данных, из Excel-файла баланса утвержденного образца либо, в случае какой-либо нестандартной информации, вводить в приложение вручную. При этом (для обеспечения необходимости отслеживания динамики показателей) следует обеспечить отдельное хранение данных за текущий и прошлый периоды;

- в связи с тем, что для организаций разной направленности, отраслей и т.п. одни и те же показатели могут рассчитываться по-разному, формулы для расчета значений показателей групп должны задаваться пользователем и также храниться в базе данных, где они могут в случае необходимости быть изменены. При запуске алгоритма оценки устойчивости будет происходить автоматическое вычисление показателей по заданным для них формулам (с использованием обратной польской записи);

- рекомендуемые для каждого конкретного случая значения каждого показателей необходимо задавать пользователем в виде функции принадлежности нечеткого множества. Предусмотреть несколько стандартных видов функций принадлежности, параметры функций вводит пользователь. В любой момент пользователь должен иметь возможность увидеть график функции принадлежности выбранного им показателя, задав интервал аргумента для ее построения; 
- с целью проведения повторных расчетов все сделанные пользователем настройки для расчета (дерево показателей, информация о статьях исходных данных, нечеткие оценки рекомендуемых значений показателей) следует сохранять в базе данных;

- после проведения расчета устойчивости пользователю должны отображаться вычисленные значения каждого из выбранного им показателей, а также их нечеткие оценки. Нечеткие оценки необходимо выводить также для групп показателей и для интегрального показателя устойчивости с учетом заданных пользователем методов их агрегации. Кроме этого, результаты расчетов должны отображаться графически, в виде иерархической структуры показателей и их групп;

- необходимо предусмотреть возможность оценки устойчивости как для предприятия целиком, так и для его отдельных подразделений, возможно, филиалов.

На основе требований к функциональным характеристикам был разработан обобщенный алгоритм работы системы поддержки принятия решений (рисунок 2). Алгоритм условно разделен на несколько этапов, каждый из которых соответствует определенной модели. Для каждого этапа были определены наименования входных и выходных данных.

В состав СППР оценки устойчивости будут входить три главных компонента: данные, база моделей и программная подсистема. Структура системы показана на рисунке 3. 

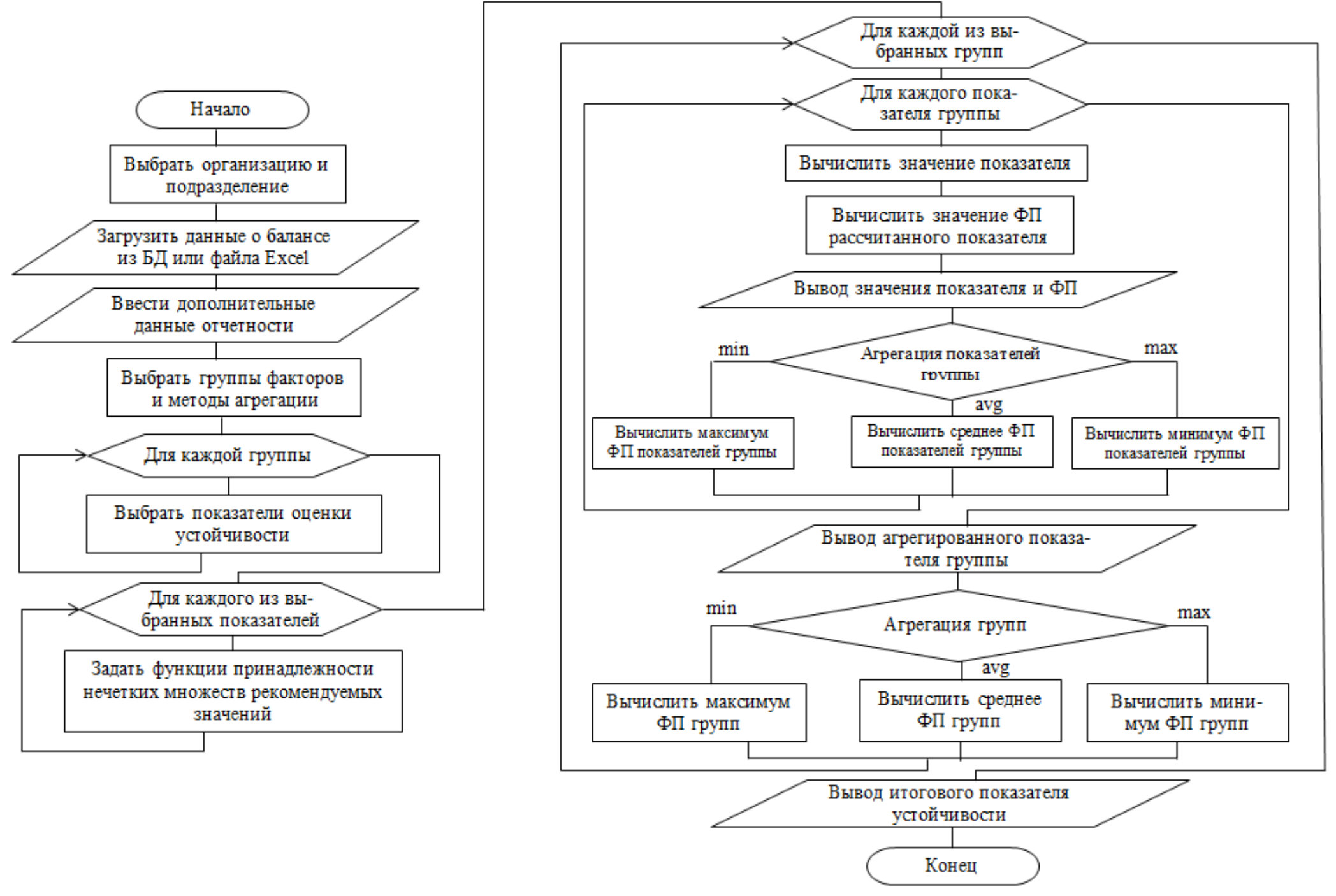

Рисунок 2 - Обобщенная блок-схема алгоритма работы СППР оценки устойчивости предприятия 
Источники данных

Програминая

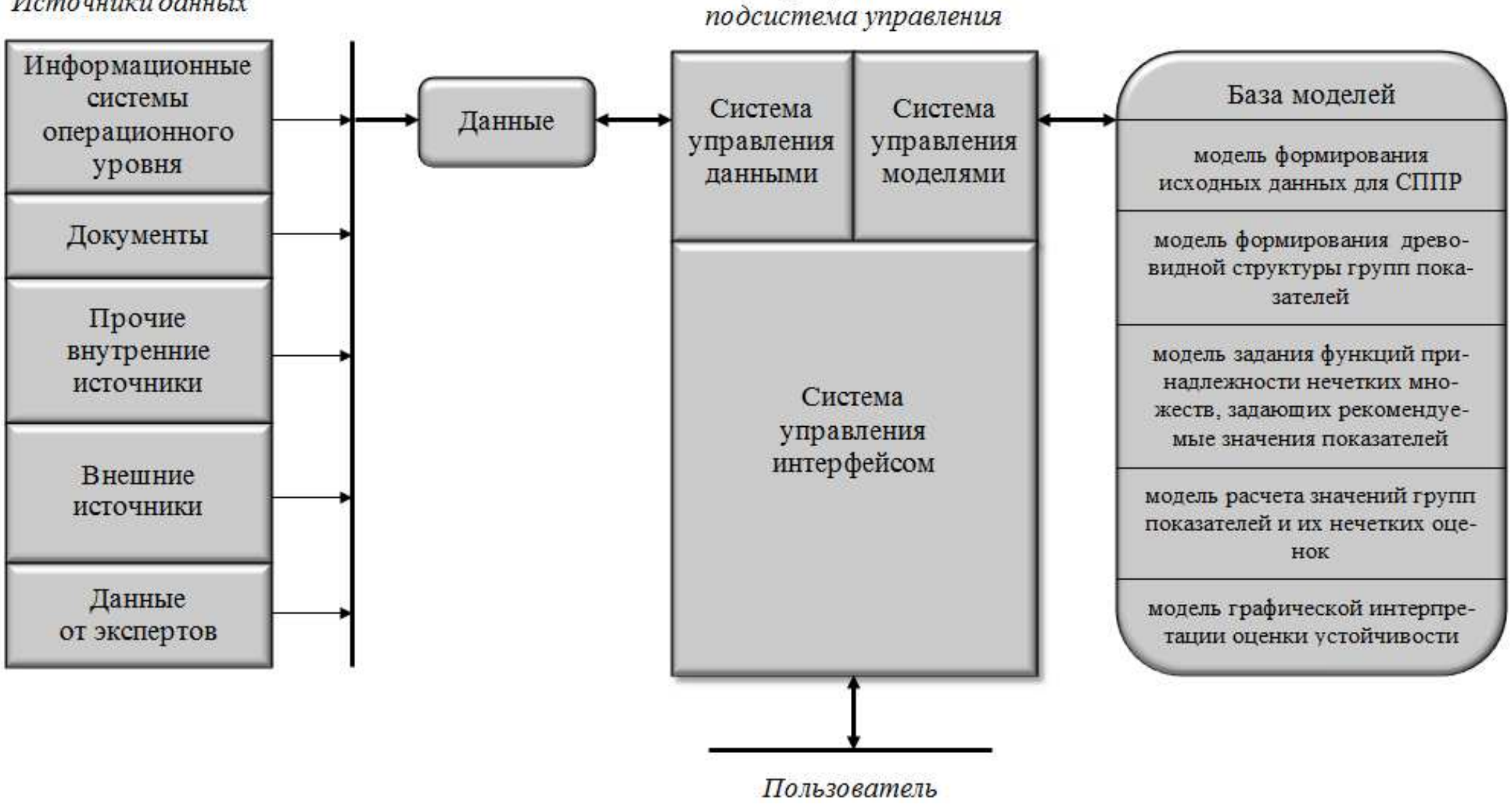

Рисунок 3 - Архитектура программного обеспечения СППР оценки устойчивости предприятия 
Данные, поступающие в систему, структурируются определенным образом и обрабатываются по заданным алгоритмам программной подсистемой управления. В зависимости от своего назначения, данные могут поступать из различных источников. Большинство источников данных внутренние, т.е. они поступают из информационных систем предприятия, из документов или прочих внешних источников. Это различные сведения об организации и ее подразделениях, прежде всего информация о результатах деятельности предприятия, которая поступает из баланса, отчета о прибылях и убытках и прочей документации, касающейся финансовой отчетности организации. Однако некоторые виды исходных данных должны браться из внешних источников. Прежде всего, это касается информации о пороговых значениях показателей для организаций различных отраслей и регионов.

Некоторые исходные данные для СППР поступают от экспертов, например, информация о видах и коэффициентах функций принадлежности нечетких множеств, задающих рекомендуемые значения показателей, необходимых для комплексной оценки устойчивости организации, а также сведения о типах агрегации показателей каждой группы и всех групп в целом.

Программная подсистема управления состоит из трех блоков: система управления данными, отвечающая за ввод/вывод и преобразование форматов данных, система управления моделями и система управления интерфейсом, основное назначение которой - обеспечение взаимодействия с пользователем (лицом, принимающим решение).

База моделей содержит в себе набор моделей, необходимых для оценки устойчивости предприятия

База данных приложения состоит из 13 связанных между собой таблиц. Создавалась она с помощью СУБД SQLite. Для создания программного обеспечения было решено использовать среду разработки Мi- 
crosoft Visual Studio 2013 и язык программирования C\#, предназначенные для выполнения в среде .NET Framework. В связи с тем, что СППР развертывается в облаке, было принято решение реализовывать систему на базе веб-приложения с использованием ASP.NET, а в качестве облачной платформы - Microsoft Azure.

Разработанная система была апробирована на предприятии ООО «Антей», при этом была проведена оценка устойчивости данной организации.

Для решения данной задачи был применен алгоритм оценки финансовой устойчивости предприятий малого бизнеса, который позволяет скоординировать результаты финансового анализа, прогнозирования банкротства и выводов о целесообразности возможного финансового оздоровления.

Диагностика финансовой устойчивости требует комплексного подхода к отбору и формированию системы ее показателей. Эта проблема решена посредством специально разработанной блоковой структуры идентификации, отражающей стратегические, краткосрочные и операционные аспекты финансовой устойчивости, создающие угрозы для общей финансовой устойчивости малого предприятия. Она включает показатели эффективности деятельности, платежеспособности, состояния погашения обязательств, уровня обеспеченности запасов и затрат экономически обоснованными источниками их покрытия с учетом влияния факторов внешней и внутренней среды.

Исходные данные для оценки устойчивости заданы в виде Excelфайлов бухгалтерского баланса и отчета о финансовых результатах. Они приведены на рисунках 4-6. 


\begin{tabular}{|c|c|c|c|c|c|}
\hline \multirow[t]{3}{*}{$\begin{array}{l}\text { Поясне- } \\
\text { ния }^{1}\end{array}$} & Наименование показателя ${ }^{2}$ & Код & На $\frac{31 \text { декабря }}{2016 \text { r. }^{3}}$ & $\begin{aligned} \text { На } 31 \text { декабря } \\
20^{\prime} 15 \text { r. }^{4}\end{aligned}$ & \begin{tabular}{|} 
На 31 декабря \\
$20^{\prime} 14$ r. $^{5}$
\end{tabular} \\
\hline & АКТИВ & \multirow[b]{3}{*}{1110} & \multirow[b]{3}{*}{38} & \multirow[b]{3}{*}{50} & \multirow[b]{3}{*}{62} \\
\hline & І. ВНЕОБОРОТНЫЕ АКТИВЫ & & & & \\
\hline & Нематериальные активы & & & & \\
\hline & Результаты исследований и разработок & 1120 & - & - & - \\
\hline & Нематериальные поисковые активы & 1130 & - & - & - \\
\hline & Материальные поисковые активы & 1140 & - & - & - \\
\hline & Основные средства & 1150 & 480 & 600 & 720 \\
\hline & $\begin{array}{l}\text { Доходные вложения в материальные } \\
\text { ценности }\end{array}$ & 1160 & - & - & - \\
\hline & Финансовые вложения & 1170 & 100 & - & - \\
\hline & Отложенные налоговые активы & 1180 & - & - & - \\
\hline & Прочие внеоборотные активы & 1190 & - & - & - \\
\hline & Итого по разделу I & 1100 & 618 & 650 & 782 \\
\hline \multicolumn{2}{|r|}{ II. ОБОРОТНЫЕ АКТИВЫ } & \multirow[b]{2}{*}{1210} & \multirow[b]{2}{*}{450} & \multirow[b]{2}{*}{380} & \multirow[b]{2}{*}{250} \\
\hline & Запасы & & & & \\
\hline & $\begin{array}{l}\text { Налог на добавленную стоимость по } \\
\text { приобретенным ценностям }\end{array}$ & 1220 & - & - & - \\
\hline & Дебиторская задолженность & 1230 & 140 & 136 & 120 \\
\hline & $\begin{array}{l}\text { Финансовые вложения (за } \\
\text { исключением денежных эквивалентов) }\end{array}$ & 1240 & - & - & - \\
\hline & $\begin{array}{l}\text { Денежные средства и денежные } \\
\text { эквиваленты }\end{array}$ & 1250 & 840 & 760 & 500 \\
\hline & Прочие оборотные активы & 1260 & - & - & - \\
\hline & Итого по разделу II & 1200 & 1430 & 1276 & 870 \\
\hline & БАЛАНС & 1600 & 2048 & 1926 & 1652 \\
\hline
\end{tabular}

\section{Рисунок 4 - Данные бухгалтерского баланса предприятия (актив)}

\begin{tabular}{|c|c|c|c|c|c|}
\hline \multirow[t]{23}{*}{$\begin{array}{c}\text { Поясне- } \\
\text { ния }^{1}\end{array}$} & Наименование показателя ${ }^{2}$ & Код & На $\frac{31 \text { декабря }}{20 \underline{16} r^{3}}$ & \begin{tabular}{|c|} 
На 31 декабря \\
2015 г. $^{4}$
\end{tabular} & \begin{tabular}{|c} 
На 31 декабря \\
2014 r.
\end{tabular} \\
\hline & ПАССИВ & & & & \\
\hline & $\begin{array}{l}\text { III. КАПИТАЛ И РЕЗЕРВЫ }{ }^{6} \\
\text { Уставный Капитал (скЛадочный } \\
\text { капитал, уставный фонд, вклады } \\
\text { товарищей) }\end{array}$ & 1310 & 500 & 500 & 500 \\
\hline & $\begin{array}{l}\text { Собственные акции, выкупленные у } \\
\text { акционеров }\end{array}$ & 1320 & )$^{7}$ & ( & ( \\
\hline & Переоценка внеоборотных активов & 1340 & - & - & - \\
\hline & Добавочный капитал (без переоценки) & 1350 & - & - & - \\
\hline & Резервный капитал & 1360 & - & - & - \\
\hline & $\begin{array}{l}\text { Нераспределенная прибыль } \\
\text { (непокрытый убыток) }\end{array}$ & 1370 & 860 & 550 & 400 \\
\hline & Итого по разделу III & 1300 & 1360 & 1050 & 900 \\
\hline & IV. ДОЛГОСРОЧНЫЕ ОБЯЗАТЕЛЬСТВА & & & & \\
\hline & Заемные средства & 1410 & 300 & 300 & - \\
\hline & Отложенные налоговые обязательства & 1420 & - & - & - \\
\hline & Оценочные обязательства & 1430 & - & - & - \\
\hline & Прочие обязательства & 1450 & - & - & - \\
\hline & Итого по разделу IV & 1400 & 300 & 300 & - \\
\hline & V. КРАТКОСРОЧНЫЕ ОБЯЗАТЕЛЬСТВА & & & & \\
\hline & Заемные средства & 1510 & 200 & - & 300 \\
\hline & Кредиторская задолженность & 1520 & 188 & 524 & 452 \\
\hline & Доходы будущих периодов & 1530 & - & - & - \\
\hline & Оценочные обязательства & 1540 & - & - & - \\
\hline & Прочие обязательства & 1550 & - & - & - \\
\hline & Итого по разделу V & 1500 & 388 & 524 & 752 \\
\hline & БАЛАНС & 1700 & 2048 & 1926 & 1652 \\
\hline
\end{tabular}

Рисунок 5 - Данные бухгалтерского баланса предприятия (пассив) 


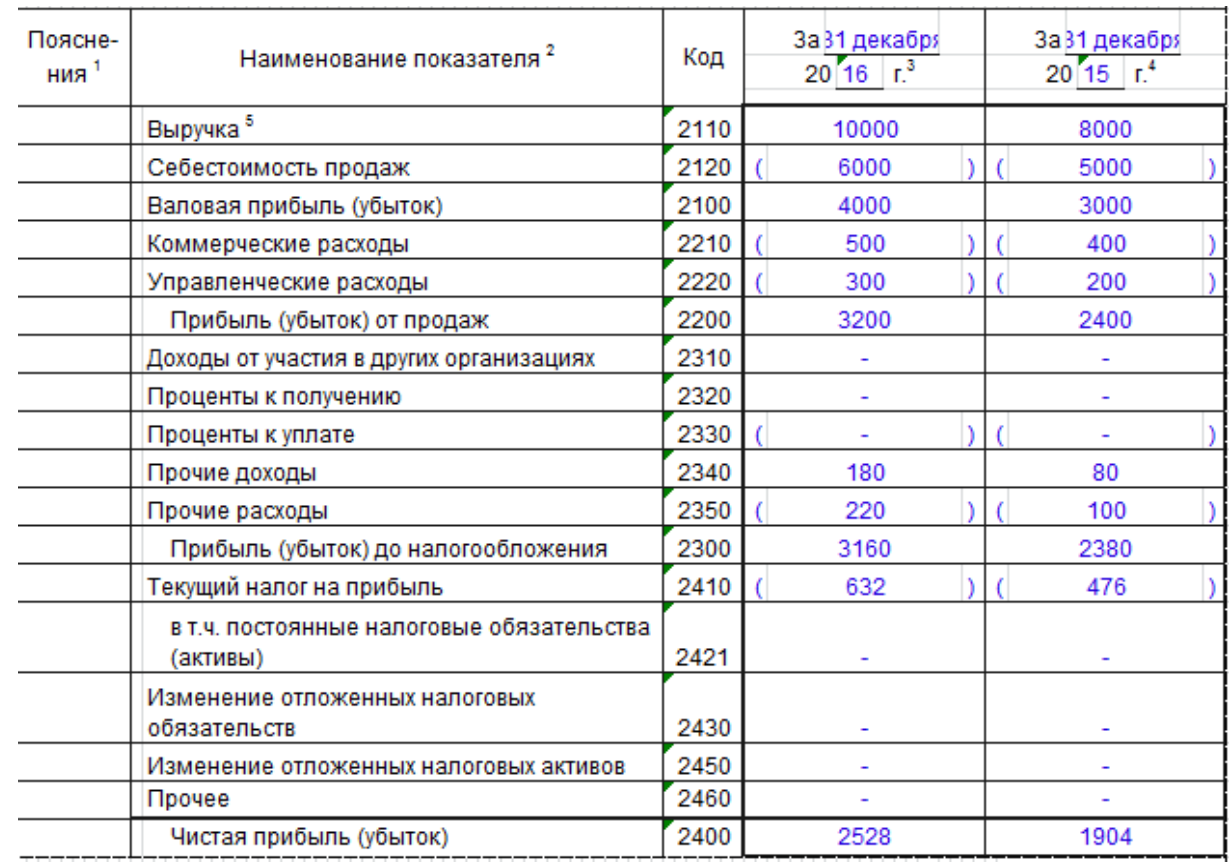

Рисунок 6 - Данные отчета о финансовых результатах

Из всех имеющихся в базе данных групп показателей для проведения компьютерного эксперимента были выбраны следующие: стратегическая устойчивость, устойчивость в краткосрочной перспективе, моментная устойчивость и показатели финансовой безопасности (рисунок 7). Все группы предполагаются равнозначными, т.е. удельный вес каждой равен 0,25. Метод агрегации показателей в каждой из групп был выбран «по среднему» (avg).

Метод агрегации всех групп при формировании интегрального показателя оценки устойчивости был задан «по минимуму» (min).

После задания набора показателей для каждой группы была получена иерархическая структура для оценки устойчивости предприятия. Она показана на рисунке 8. 
Группы факторов

\begin{tabular}{|l|l|l|l|}
\hline & Наименование & Bec & Aгрегаци: \\
\hline$\square$ & инновационная устойчиво... & 0 & min \\
\hline$\square$ & Моментная устойчивость & 0,25 & avg \\
\hline$\square$ & наличие у предлриятия ре... & 0 & min \\
\hline$\square$ & Показатели финансовой ... & 0,25 & avg \\
\hline$\square$ & социальная устойчивость & 0 & min \\
\hline$\square$ & Стратегическая устойчив... & 0,25 & avg \\
\hline$\square$ & темпы роста интенсифик... & 0 & min \\
\hline$\square$ & Устойчивость в краткоср... & $0,25 \mid$ & avg \\
\hline$\square$ & экологическая устойчиво... & 0 & min \\
\hline$\square$ & экономическая утойчивос... & 0 & min \\
$<$ & & & \\
\hline
\end{tabular}

Рисунок 7 - Выбранные группы показатели и их характеристики

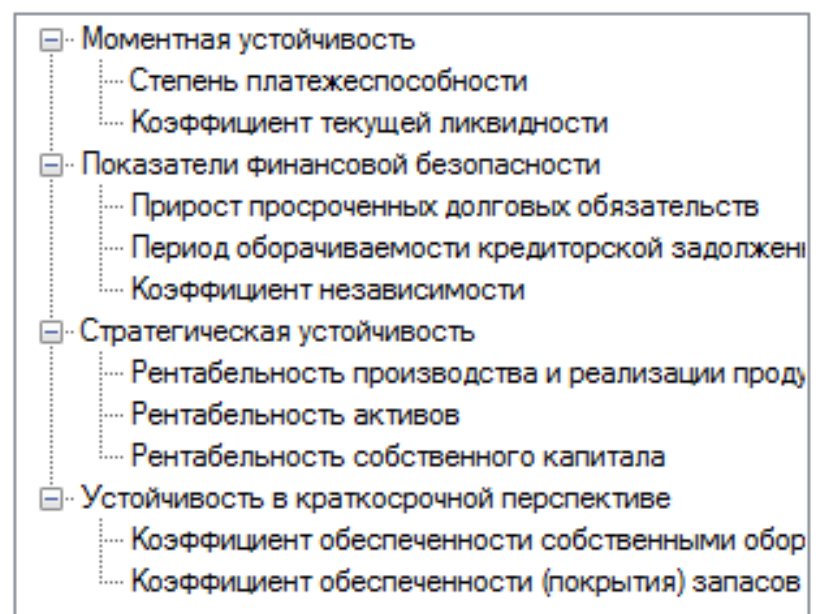

Рисунок 8 - Иерархическая структура для оценки устойчивости

В соответствии с рекомендуемыми в общероссийской практике нормативными значениями коэффициентов, при проведении компьютерного эксперимента были заданы следующие значения функций принадлежности нечетких множеств, задающих рекомендуемые значения коэффициентов (таблица 1). 
Таблица 1 - Нечеткая оценка рекомендуемых значений показателей

\begin{tabular}{|l|l|c|c|c|c|}
\hline \multicolumn{1}{|c|}{ Показатель } & \multicolumn{1}{|c|}{ Тип ФП } & $\begin{array}{c}\text { Параметр } \\
1\end{array}$ & $\begin{array}{c}\text { Параметр } \\
2\end{array}$ & $\begin{array}{c}\text { Параметр } \\
3\end{array}$ & $\begin{array}{c}\text { Параметр } \\
4\end{array}$ \\
\hline $\begin{array}{l}\text { Степень платеже- } \\
\text { способности }\end{array}$ & Z-образная & 3 & 12 & - & - \\
\hline $\begin{array}{l}\text { Коэффициент теку- } \\
\text { щей ликвидности }\end{array}$ & $\begin{array}{l}\text { Трапецие- } \\
\text { видная }\end{array}$ & $-0,5$ & 2 & 3 & 5 \\
\hline $\begin{array}{l}\text { Прирост просрочен- } \\
\text { ных долговых обяза- } \\
\text { тельств }\end{array}$ & Z-образная & 0,5 & 5 & - & - \\
\hline $\begin{array}{l}\text { Период оборачивае- } \\
\text { мости кредиторской } \\
\text { задолженности, дней }\end{array}$ & Z-образная & 90 & 200 & - & - \\
\hline $\begin{array}{l}\text { Коэффициент неза- } \\
\text { висимости }\end{array}$ & $\begin{array}{l}\text { Трапецие- } \\
\text { видная }\end{array}$ & 0 & 0,6 & 3 & 20 \\
\hline $\begin{array}{l}\text { Рентабельность про- } \\
\text { изводства и реализа- } \\
\text { ции продукции }\end{array}$ & S-образная & 0 & 1 & - & - \\
\hline $\begin{array}{l}\text { Рентабельность ак- } \\
\text { тивов }\end{array}$ & S-образная & 0 & 3 & - & - \\
\hline $\begin{array}{l}\text { Рентабельность соб- } \\
\text { ственного капитала }\end{array}$ & $\begin{array}{l}\text { Сигмоид- } \\
\text { ная }\end{array}$ & 2 & 0 & - & - \\
\hline $\begin{array}{l}\text { Коэффициент обес- } \\
\text { печенности соб- } \\
\text { ственными оборот- } \\
\text { ными средствами }\end{array}$ & $\begin{array}{l}\text { Колоколо- } \\
\text { образная }\end{array}$ & 0,5 & 2 & 0,5 & - \\
\hline $\begin{array}{l}\text { Коэффициент обес- } \\
\text { печенности (покры- } \\
\text { тия) запасов и затрат }\end{array}$ & $\begin{array}{l}\text { Сигмоид- } \\
\text { ная }\end{array}$ & 4 & 1 & - & \\
\hline
\end{tabular}

После формирования всех исходных данных для СППР по заданным формулам рассчитываются значения каждого из выбранных коэффициентов, вычисляется соответствующее ему значение функции принадлежности, после чего выполняется агрегация коэффициентов в группы с учетом выбранных способов агрегации. А затем, после агрегации групп, определяется значение итогового показателя устойчивости. Его результирующее значение можно интерпретировать следующим образом (таблица 2). 
Таблица 2 - Значения итогового показателя устойчивости

\begin{tabular}{|c|l|}
\hline Интервалы & \multicolumn{1}{|c|}{ Заключение об устойчивости предприятия } \\
\hline $0,0-0,2$ & Предельный риск банкротства \\
\hline $0,2-0,4$ & Высокий риск банкротства \\
\hline $0,4-0,6$ & Средний риск банкротства \\
\hline $0,6-0,8$ & Устойчивое состояние \\
\hline $0,8-1,0$ & Абсолютная устойчивость \\
\hline
\end{tabular}

Вычисленные для нашего эксперимента результаты приведены в таблице 3. Для наглядности отображения полученных результатов они представляются не только в табличном, но и в графическом виде (рисунок 9). Степень насыщенности зеленого цвета для каждого узла дерева отражает оценку его устойчивости.

Из полученных данных видно, что полученное значение 0,633 для рассматриваемого предприятия оценивается как «устойчивое состояние».

Таблица 3 - Результаты компьютерного эксперимента

\begin{tabular}{|l|c|c|c|}
\hline \multicolumn{1}{|c|}{ Наименование показателя (группы) } & Агрегация & Значение & $\begin{array}{c}\text { 3начение } \\
\text { ФП }\end{array}$ \\
\hline Степень платежеспособности (Сп) & & 0,466 & 1 \\
\hline Коэффициент текущей ликвидности (Кл) & & 3,943 & 0,528 \\
\hline Моментная устойчивость & avg & & $\mathbf{0 , 7 6 4}$ \\
\hline $\begin{array}{l}\text { Прирост просроченных долговых обязательств } \\
\text { (Ппдо) }\end{array}$ & & 2,556 & 0,568 \\
\hline $\begin{array}{l}\text { Период оборачиваемости кредиторской задол- } \\
\text { женности, дней (Покз) }\end{array}$ & & 12,994 & 1 \\
\hline Коэффициент независимости (Кнез) & avg & 0,664 & 1 \\
\hline Показатели финансовой безопасности & & 0,533 & 0,552 \\
\hline $\begin{array}{l}\text { Рентабельность производства и реализации } \\
\text { продукции (Рпр) }\end{array}$ & & 1,234 & 0,363 \\
\hline Рентабельность активов (Ра) & avg & & 0,985 \\
\hline Рентабельность собственного капитала (Рск) & & 0,729 & 0,958 \\
\hline Стратегическая устойчивость & & 1,649 & 0,931 \\
\hline $\begin{array}{l}\text { Коэффициент обеспеченности собственными } \\
\text { оборотными средствами (Косос) }\end{array}$ & & & $\mathbf{0 , 9 4 4}$ \\
\hline $\begin{array}{l}\text { Коэффициент обеспеченности (покрытия) за- } \\
\text { пасов и затрат (Кпзз) }\end{array}$ & min & $\mathbf{0 , 6 3 3}$ \\
\hline Устойчивость в краткосрочной перспективе & & & \\
\hline Итоговый показатель устойчивости & & & \\
\hline
\end{tabular}




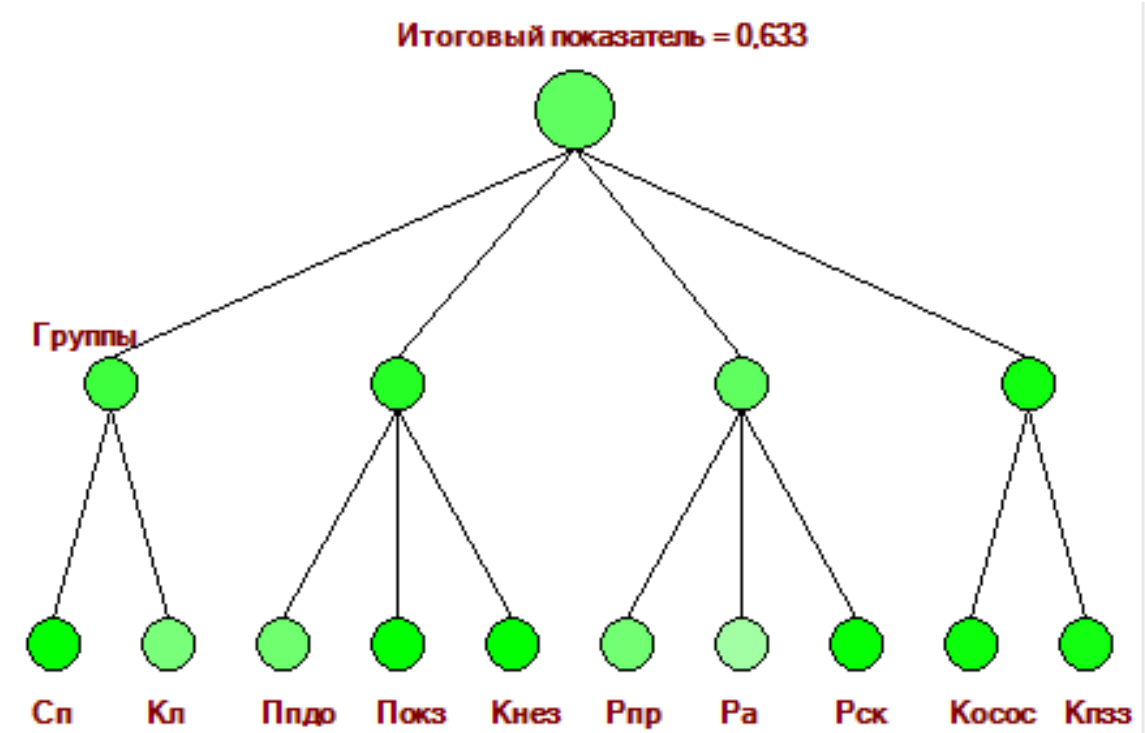

Рисунок 9 - Графическая интерпретация оценки устойчивости

Таким образом, описанные выше особенности архитектуры и реализации СППР, такие, как: возможность пользователю самому задавать набор показателей и их групп для оценки устойчивости (т.е. фактически генерировать алгоритм данного процесса), возможность применять нечеткие оценки пороговых значений показателей, - позволяют использовать разработанную систему для оценки устойчивости организаций различных форм собственности, отраслей и расположенных в разных регионах.

\section{ЛИТЕРАТУРА}

1. Коршунова Э.Т. Порядок оценки устойчивости экономического развития промышленного предприятия // Экономические науки. 2013. № 1. - С. 81.

2. Сидоренко Л.Ж. Методы оценки финансовой устойчивости предприятий малого бизнеса и факторов, влияющих на нее, в условиях современной России: Автореф. дис. канд. экон. наук. - Майкоп: НОУ ВПО «Институт управления, бизнеса и права», 2011. $-27 \mathrm{c}$.

3. Козлова, Е.М. Устойчивость промышленного предприятия: виды, структурные компоненты и инструментарий оценки [Электронный ресурс] / Е.М. Козлова // Известия Оренбургского государственного аграрного университета. - 2014. - № 1 . - Режим доступа: http://cyberleninka.ru/article/n/ ustoychivost-promyshlennogo-predpriyatiya-vidystrukturnye-komponenty-i-instrumentariy-otsenki

4. Кулакова, Н.Н. Анализ финансовой устойчивости предприятия [Электронный pecypc] / Н.Н. Кулакова // Вектор науки Тольяттинского государственного университе- 


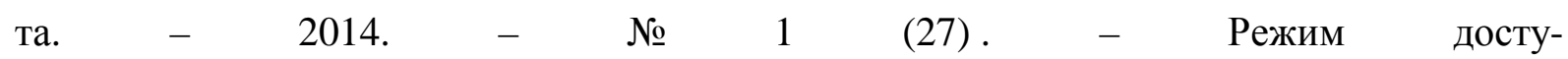
па: http://journal.tltsu.ru/rus/index.php/Vectorscience/article/view/1331

5. Магомедова, М. Оценка устойчивого развития предприятий моделями дескриптивного и предикативного типа [Электронный ресурс] / М. Магомедова // Московский экономический журнал. - 2016. - № 2. - Режим доступа: http://qje.su/upravleniepredpriyatiem/moskovskij-ekonomicheskij-zhurnal-1-2016-12/

6. Набиев, А.М. Комплексная оценка устойчивости предприятий [Электронный peсурс] / А.М. Набиев // Вестник Челябинского государственного университета. - 2002. - выпуск 2, том 8. - Режим доступа: http://cyberleninka.ru/article/n/kompleksnayaotsenka-ustoychivosti-predpriyatiy

7. Хомяченкова Н.А. Методика многокритериальной классификации промышленных предприятий по группам устойчивого развития // Вестник Тверского государственного университета. Серия: Прикладная математика. 2010. № 37. - С. 81.

8. Барановская Т.П. Архитектура системы поддержки принятия решений обоснования объемов кредитования малых сельскохозяйственных предприятий / Т.П. Барановская, Е.А. Иванова, В.Е. Сайкинов // Политематический сетевой электронный научный журнал Кубанского государственного аграрного университета (Научный журнал КубГАУ) [Электронный ресурс]. - Краснодар: КубГАУ, 2015. - №08(112). С. 2035 - 2047. - IDA [article ID]: 1121508146. - Режим доступа: http://ej.kubagro.ru/2015/08/pdf/146.pdf, 0,812 у.п.л.

9. Разработка бизнес-приложений. Методические указания к выполнению лабораторных работ для студентов четвертого курса специальности «Информационные системы и технологии» / Сост. Е.А. Иванова, Н.В. Ефанова, 2012. - 85 с.

10.Теория систем и системный анализ: разработка и оценка организационных структур: метод. пособие / Барановская Т. П., Вострокнутов А. Е. - Краснодар: КубГАУ, 2011.

11.Барановская Т.П. Разработка и исследование моделей бизнес-архитектуры подсистемы продаж корпоративной интегрированной структуры / Т.П. Барановская, А.Е. Вострокнутов // Политематический сетевой электронный научный журнал Кубанского государственного аграрного университета (Научный журнал КубГАУ) [Электронный ресурс]. - Краснодар: КубГАУ, 2015. - №08(112). С. 1934 - 1960. - IDA [article ID]: 1121508140. - Режим доступа: http://ej.kubagro.ru/2015/08/pdf/140.pdf, 1,688 у.п.л.

12.Моделирование бизнес-процессов: учеб. пособие / Т.П. Барановская, И.М. Яхонтова, А.Е. Вострокнутов, Е.А. Иванова. - Краснодар, 2016. - 154 с.

13.Мурлин А.Г. Программирование на языке Си++: учеб. пособие / А.Г. Мурлин, В.А. Мурлина, Н.В. Ефанова, Е.А. Иванова. - Краснодар, КубГАУ, 2016. - 186 с.

14.Ефанова Н.В. Элементы теории нечетких множеств : учеб. пособие / Н.В. Ефанова, Е.А. Иванова. - Краснодар: КубГАУ, 2017. - 202 с.

15. Маяков В.А., Иванова Е.А. Сравнительная характеристика основных платформ облачных вычислений. // «Информационное общество: современное состояние и перспективы развития». Сборник материалов VIII международного форума. - Краснодар, 2017. - с. 358-360.

16.Барановская Т.П. Перспективы развертывания системы поддержки принятия решений обоснования объемов кредитования малых сельскохозяйственных предприятий в облачной среде / Т.П. Барановская, Е.А. Иванова, В.Е. Сайкинов // Политематический сетевой электронный научный журнал Кубанского государственного аграрного университета (Научный журнал КубГАУ) [Электронный ресурс]. - Краснодар: КубГАУ, 2015. - №08(112). С. 2048 - 2060. - IDA [article ID]: 1121508147. - Режим доступа: http://ej.kubagro.ru/2015/08/pdf/147.pdf, 0,812 у.п.л. 
17.Барановская Т.П. Разработка автоматизированной системы работы с клиентами для ООО «Кайрос» / Т.П. Барановская, Е.А. Иванова, К.А. Головко // Политематический сетевой электронный научный журнал Кубанского государственного аграрного университета (Научный журнал КубГАУ) [Электронный ресурс]. - Краснодар: КубГАУ, 2016. - №05(119). С. 1453 - 1466. - IDA [article ID]: 1191605097. - Режим доступа: http://ej.kubagro.ru/2016/05/pdf/97.pdf, 0,875 у.п.л.

18.Разработка приложений на языках высокого уровня. Методические указания к лабораторным работам для студентов первого курса специальности 351400 «Прикладная информатика (по областям)» всех форм обучения. - Краснодар, КубГАУ, 2004.

19.Основы объектно-ориентированного программирования. Методические указания к лабораторным работам по дисциплине «Объектно-ориентированный анализ и программирование». - Краснодар, КубГАУ, 2012. - 89 с.

20.Рыбалко М.А., Иванова Е.А. Тестирование программного обеспечения, методы тестирования. // «Информационное общество: современное состояние и перспективы развития». Сборник материалов VIII международного форума. - Краснодар, 2017. - с. 320-322.

21.Барановская Т.П. Автоматизированная подсистема планирования бюджета рекламной кампании / Т.П. Барановская, Е.А. Иванова, Ф.Р. Хачак // Политематический сетевой электронный научный журнал Кубанского государственного аграрного университета (Научный журнал КубГАУ) [Электронный ресурс]. - Краснодар: КубГАУ, 2016. - №06(120). C. 223 - 238. - IDA [article ID]: 1201606013. - Режим доступа: http://ej.kubagro.ru/2016/06/pdf/13.pdf, 1 у.п.л.

\section{References}

1. Korshunova Je.T. Porjadok ocenki ustojchivosti jekonomicheskogo razvitija promyshlennogo predprijatija // Jekonomicheskie nauki. 2013. № 1. - S. 81.

2. Sidorenko L.Zh. Metody ocenki finansovoj ustojchivosti predprijatij malogo biznesa i faktorov, vlijajushhih na nee, v uslovijah sovremennoj Rossii: Avtoref. dis. kand. jekon. nauk. - Majkop: NOU VPO «Institut upravlenija, biznesa i prava», 2011. — 27 s.

3. Kozlova, E.M. Ustojchivost' promyshlennogo predprijatija: vidy, strukturnye komponenty i instrumentarij ocenki [Jelektronnyj resurs] / E.M. Kozlova // Izvestija Orenburgskogo gosudarstvennogo agrarnogo universiteta. - 2014. - № 1 . - Rezhim dostupa: http://cyberleninka.ru/article/n/ ustoychivost-promyshlennogo-predpriyatiya-vidystrukturnye-komponenty-i-instrumentariy-otsenki

4. Kulakova, N.N. Analiz finansovoj ustojchivosti predprijatija [Jelektronnyj resurs] / N.N. Kulakova // Vektor nauki Tol'jattinskogo gosudarstvennogo universiteta. - 2014. - № 1 (27) . - Rezhim dostupa: http://journal.tltsu.ru/rus/index.php/Vectorscience/article/view/1331

5. Magomedova, M. Ocenka ustojchivogo razvitija predprijatij modeljami deskriptivnogo i predikativnogo tipa [Jelektronnyj resurs] / M. Magomedova // Moskovskij jekonomicheskij zhurnal. - 2016. - № 2. - Rezhim dostupa: http://qje.su/upravleniepredpriyatiem/moskovskij-ekonomicheskij-zhurnal-1-2016-12/

6. Nabiev, A.M. Kompleksnaja ocenka ustojchivosti predprijatij [Jelektronnyj resurs] / A.M. Nabiev // Vestnik Cheljabinskogo gosudarstvennogo universiteta. - 2002. - vypusk 2, tom 8 - - Rezhim dostupa: http://cyberleninka.ru/article/n/kompleksnaya-otsenkaustoychivosti-predpriyatiy

7. Homjachenkova N.A. Metodika mnogokriterial'noj klassifikacii promyshlennyh predprijatij po gruppam ustojchivogo razvitija // Vestnik Tverskogo gosudarstvennogo universiteta. Serija: Prikladnaja matematika. 2010. № 37. - S. 81.

8. Baranovskaja T.P. Arhitektura sistemy podderzhki prinjatija reshenij obosnovanija ob\#emov kreditovanija malyh sel'skohozjajstvennyh predprijatij / T.P. Baranovskaja, E.A. 
Ivanova, V.E. Sajkinov // Politematicheskij setevoj jelektronnyj nauchnyj zhurnal Kubanskogo gosudarstvennogo agrarnogo universiteta (Nauchnyj zhurnal KubGAU) [Jelektronnyj resurs]. - Krasnodar: KubGAU, 2015. - №08(112). S. 2035 - 2047. - IDA [article ID]: 1121508146. - Rezhim dostupa: http://ej.kubagro.ru/2015/08/pdf/146.pdf, 0,812 u.p.l.

9. Razrabotka biznes-prilozhenij. Metodicheskie ukazanija k vypolneniju laboratornyh rabot dlja studentov chetvertogo kursa special'nosti «Informacionnye sistemy i tehnologii» / Sost. E.A. Ivanova, N.V. Efanova, 2012. - 85 s.

10. Teorija sistem i sistemnyj analiz: razrabotka i ocenka organizacionnyh struktur: metod. posobie / Baranovskaja T. P., Vostroknutov A. E. - Krasnodar: KubGAU, 2011.

11.Baranovskaja T.P. Razrabotka i issledovanie modelej biznes-arhitektury podsistemy prodazh korporativnoj integrirovannoj struktury / T.P. Baranovskaja, A.E. Vostroknutov // Politematicheskij setevoj jelektronnyj nauchnyj zhurnal Kubanskogo gosudarstvennogo agrarnogo universiteta (Nauchnyj zhurnal KubGAU) [Jelektronnyj resurs]. - Krasnodar: KubGAU, 2015. - №08(112). S. 1934 - 1960. - IDA [article ID]: 1121508140. - Rezhim dostupa: http://ej.kubagro.ru/2015/08/pdf/140.pdf, 1,688 u.p.l.

12. Modelirovanie biznes-processov: ucheb. posobie / T.P. Baranovskaja, I.M. Jahontova, A.E. Vostroknutov, E.A. Ivanova. - Krasnodar, 2016. - 154 s.

13. Murlin A.G. Programmirovanie na jazyke Si++: ucheb. posobie / A.G. Murlin, V.A. Murlina, N.V. Efanova, E.A. Ivanova. - Krasnodar, KubGAU, 2016. - 186 s.

14. Efanova N.V. Jelementy teorii nechetkih mnozhestv : ucheb. posobie / N.V. Efanova, E.A. Ivanova. - Krasnodar: KubGAU, 2017. - 202 s.

15. Majakov V.A., Ivanova E.A. Sravnitel'naja harakteristika osnovnyh platform oblachnyh vychislenij. // «Informacionnoe obshhestvo: sovremennoe sostojanie i perspektivy razvitija». Sbornik materialov VIII mezhdunarodnogo foruma. - Krasnodar, 2017. - s. 358360.

16. Baranovskaja T.P. Perspektivy razvertyvanija sistemy podderzhki prinjatija reshenij obosnovanija ob\#emov kreditovanija malyh sel'skohozjajstvennyh predprijatij v oblachnoj srede / T.P. Baranovskaja, E.A. Ivanova, V.E. Sajkinov // Politematicheskij setevoj jelektronnyj nauchnyj zhurnal Kubanskogo gosudarstvennogo agrarnogo universiteta (Nauchnyj zhurnal KubGAU) [Jelektronnyj resurs]. - Krasnodar: KubGAU, 2015. - №08(112). S. 2048 - 2060. - IDA [article ID]: 1121508147. - Rezhim dostupa: http://ej.kubagro.ru/2015/08/pdf/147.pdf, 0,812 u.p.l.

17. Baranovskaja T.P. Razrabotka avtomatizirovannoj sistemy raboty s klientami dlja OOO «Kajros» / T.P. Baranovskaja, E.A. Ivanova, K.A. Golovko // Politematicheskij setevoj jelektronnyj nauchnyj zhurnal Kubanskogo gosudarstvennogo agrarnogo universiteta (Nauchnyj zhurnal KubGAU) [Jelektronnyj resurs]. - Krasnodar: KubGAU, 2016. - №05(119). S. 1453 - 1466. - IDA [article ID]: 1191605097. - Rezhim dostupa: http://ej.kubagro.ru/2016/05/pdf/97.pdf, 0,875 u.p.1.

18. Razrabotka prilozhenij na jazykah vysokogo urovnja. Metodicheskie ukazanija k laboratornym rabotam dlja studentov pervogo kursa special'nosti 351400 «Prikladnaja informatika (po oblastjam)» vseh form obuchenija. - Krasnodar, KubGAU, 2004.

19. Osnovy ob\#ektno-orientirovannogo programmirovanija. Metodicheskie ukazanija $\mathrm{k}$ laboratornym rabotam po discipline «Ob\#ektno-orientirovannyj analiz i programmirovanie». - Krasnodar, KubGAU, 2012. - 89 s.

20.Rybalko M.A., Ivanova E.A. Testirovanie programmnogo obespechenija, metody testirovanija. // «Informacionnoe obshhestvo: sovremennoe sostojanie i perspektivy razvitija». Sbornik materialov VIII mezhdunarodnogo foruma. - Krasnodar, 2017. - s. 320-322.

21.Baranovskaja T.P. Avtomatizirovannaja podsistema planirovanija bjudzheta reklamnoj kampanii / T.P. Baranovskaja, E.A. Ivanova, F.R. Hachak // Politematicheskij setevoj 
jelektronnyj nauchnyj zhurnal Kubanskogo gosudarstvennogo agrarnogo universiteta (Nauchnyj zhurnal KubGAU) [Jelektronnyj resurs]. - Krasnodar: KubGAU, 2016. - №06(120). S. 223 - 238. - IDA [article ID]: 1201606013. - Rezhim dostupa: http://ej.kubagro.ru/2016/06/pdf/13.pdf, 1 u.p.1. 